\title{
Autonomía, democracia e igualdad
}

\author{
Autonomy, Democracy and Equality
}

Martín Aldao**

Fecha de presentación del texto, primera versión: 11/09/15.

Fecha de entrega de revisiones: 18/12/2015.

Fecha de entrega del texto final, revisado: 18/02/2015.

Resumen: En lo que sigue voy a explorar el potencial explicativo y normativo de la tesis de la argumentación autónoma de Jan Sieckmann. Con ese propósito, en una primera parte se propone una reconstrucción de la tesis de la argumentación autónoma en el marco de una comprensión deliberativa de la democracia y una teoría no positivista del derecho. En la segunda parte se analizan dos procesos políticos constitucionales con el objetivo de probar el marco conceptual desarrollado en la primera parte.

Palabras claves: argumentación autónoma, democracia e igualdad.

\begin{abstract}
In this paper I will explore the explicative and normative potential of Jan Sieckmann's autonomous argumentation. Whit that purpose, in the first part I propose a reconstruction of the thesis of the autonomous argumentation within deliberative understanding of democracy and a non-positivist theory of law. In the second part, I analyze two constitutional political processes, with the aim of proving the conceptual frame developed in the first part.
\end{abstract}

Keywords: autonomous argumentation, democracy, equality.

* Agradezco los comentarios de Laura Clérico y Federico De Fazio.

** Instituto A. L. Gioja, Facultad de Derecho-UBA. 


\section{La tesis de la argumentación autónoma en el marco de una teoría comprensiva del estado democrático de derecho}

La tesis de la argumentación autónoma permite comprender mejor la conexión entre la teoría de los derechos fundamentales, la teoría de la argumentación jurídica y la teoría deliberativa de la democracia. Así responde a los siguientes problemas: $i$. la conexión entre el derecho y la moral, ii. el problema del consenso y las mayorías, iii. el lugar de los derechos fundamentales y $i v$. la función del poder judicial en un estado democrático.

\section{I.1 Una perspectiva no metafísica sobre la conexión entre la moral y el derecho}

La propuesta de Jan Sieckmann se inscribe en lo que podríamos denominar un paradigma fuerte de democracia deliberativa. Por paradigma fuerte se entiende una reconstrucción del proceso político que, desde una perspectiva intersubjetiva de la racionalidad o racionalidad argumentativa, ubica a la deliberación como condición de posibilidad de la democracia ${ }^{1}$.

De este modo permite conectar el concepto de legitimidad del derecho con la idea de democracia en el seno de la teoría del derecho, permitiendo una reconstrucción no metafísica ${ }^{2}$ del vínculo entre derecho y moral. En este sentido el trabajo constituye un notable aporte a

1 Por otro lado, un paradigma débil de la democracia deliberativa, tal como el de John Rawls, o el que presenta Carlos Nino en La Constitución de la Democracia Deliberativa, tienden a considerar a la deliberación como un mecanismo de mejora epistémica en el proceso de producción de las normas: deseable, pero no imprescindible. Ver Aldao, M. "Teoría de la argumentación y democracia", Revista Gioja, 1, 2007

2 Me refiero a no metafísica en tanto el trabajo de Sieckmann reconstruye un sistema de toma de decisiones políticamente legítimas y por ende vinculantes sin recurrir a otra cosa que a la existencia de individuos autónomos portadores de intereses. No hay invocaciones a una moral objetiva, ni al altruismo, ni al concepto de pueblo, ni a ninguna otra entidad ideal. Aún la concepción de racionalidad de la teoría del discurso es notablemente simple. 
lo que podríamos denominar una teoría democrática del derecho ${ }^{3}$, en el camino iniciado por J. Habermas y R. Alexy ${ }^{4}$.

Desde la teoría del discurso, la corrección de una proposición normativa no depende de su correspondencia con una moral objetiva, no obstante lo cual resulta posible introducir valores (bajo la forma de intereses de los interlocutores) en la argumentación, de un modo similar $^{5}$ al que utilizamos para introducir datos empíricos. La diferencia radica en que, mientras para los últimos utilizamos como criterio de evaluación la validación de la disciplina científica correspondiente (peritajes, datos estadísticos, etc.), para los primeros recurrimos, en última instancia, al criterio de imparcialidad, es decir, el igual respeto y consideración de los intereses de cada hablante, aplicado a través de la deliberación pública. A su vez, en tanto la introducción de valores presupone la autonomía de los individuos involucrados, y la participación en el discurso implica que cada individuo está obligado ${ }^{6}$ a reconocer la autonomía del resto -de otro modo no sería una argumentación-, tenemos entonces una serie de criterios procedimentales que permiten evaluar las preferencias morales de los participantes en el discurso en términos de imparcialidad ${ }^{7}$.

3 Ver Aldao, M. "Racionalidad, derecho y democracia", en Clérico, L. y Sieckmann, J. (eds.) La teoría del Derecho de Hans Kelsen, Bogotá, Externado, 2011.

${ }^{4} \mathrm{El}$ trabajo reconoce antecedentes en Sieckman, J. R., The logic of autonomy, Oxford, Hart Pub., 2012; antes en "El concepto de autonomía", Doxa, 31, 2008; y en "Basic Rights in the Model of Principles", IVR, ARSP, 67, 1997. op.cit.

5 Aunque no idéntico, ver Sieckmann, J. op.cit., 2008, pág. 470.

6 La naturaleza de esta obligación es probablemente uno de los puntos más discutidos de la teoría de la argumentación. Un análisis riguroso del problema puede encontrarse en el artículo Habermas, J. "Ética del Discurso: notas sobre un programa de fundamentación" en Conciencia moral y acción comunicativa, Madrid, Trotta, 2008.

7 A través de la introducción del criterio de universabilidad. Es relevante notar que se trata de un modo de abordar -y no de resolver- cuestiones morales, ya que no pretende -ni puede- dar una respuesta definitiva a todos los conflictos morales, políticos, culturales o religiosos que puedan darse. Como reacción al escepticismo moral, lo único que pretende la teoría del 
Así el tercer elemento de la argumentación autónoma consiste en:

La reflexión intersubjetiva respecto de las diversas concepciones normativas de los agentes autónomos, considerando la situación de conflicto de las diversas opiniones y evaluando cuál sea la norma adecuada para ésta situación. Deben ser juicios autónomos, aunque tomando un punto de vista imparcial, que considere todas las concepciones normativas relevantes como igualmente válidas e importantes ${ }^{8}$.

A su vez, la tesis de la argumentación autónoma tal como es presentada por Jan Sieckmann permite ver no solo la analogía estructural entre la producción de derecho legítimo y la argumentación racional, sino también el modo concreto en que interactúan los principios de autonomía individual y de soberanía popular que se encuentran a la base de lo que Habermas denomina con cierta vaguedad "génesis democrática del derecho"9.

\section{2 Consenso argumentado y consenso mayoritario}

A su vez el principio de universabilidad que se encuentra a la base de la tesis de la argumentación autónoma nos permite trazar una distinción que resulta de la mayor importancia cuando analizamos las instituciones democráticas. Desde una comprensión deliberativa, el quid de la democracia no radica en las mayorías, sino en la imparcialidad.

discurso es que existe la posibilidad de una argumentación racional en temas morales, el que esta argumentación llegue a un único resultado, y que además este único resultado satisfaga las preferencias de todos los involucrados es algo que depende, fundamentalmente, de la homogeneidad moral, cultural, política, ideológica y religiosa de los involucrados antes que de cualquier mecanismo institucional de organización colectiva. Para una sobreestimación del modelo ver por ejemplo Oquendo, A. "El dilema entre la autonomía pública y la privada: reflexiones y contra-reflexiones", Revista Jurídica de la Universidad de Palermo, n. ${ }^{\circ} 4,1999$.

8 Sieckmann, J. "Autonomía moral y legitimidad democrática", V. 2. 
El peso que atribuimos al argumento mayoritario proviene en realidad de la repetida idea de que la asamblea legislativa -0 el parlamento- es el locus de la democracia, idea que no puede ser afirmada sin más. De hecho se trata de una distorsión operada por Sieyes sobre las ideas de Rousseau a partir de la publicación de ¿Qué es el tercer estado? en 1789, con el propósito de acomodar las ideas del Contrato Social al naciente estado revolucionario. Al igual que en el análisis de Sieckmann, para Rousseau el único modo de preservar el ejercicio de la autonomía (que él denomina libertad) dentro de una organización política radica en la libre manifestación de la voluntad de los ciudadanos en tanto individuos, a través del mecanismo universabilizador de la ley ${ }^{10}$ de modo que el cuerpo de los súbditos y el de los soberanos queden identificados.

Por el contrario Sieyes propone un cambio explícitamente proscripto en el Contrato Social: la asimilación de la voluntad general con la voluntad de la mayoría. Este recurso, no obstante su evidente utilidad, es en todo caso un instrumento razonable para agilizar la argumentación, pero no puede reclamar para sí la capacidad de resolver definitivamente las argumentaciones normativas.

Las debilidades de la argumentación en torno a los problemas para realizar un discurso ideal, de su capacidad de encontrar soluciones normativas y de garantizar su cumplimiento, requieren reconocer una autoridad política que pueda tomar decisiones vinculantes. Sin embargo, la necesidad de reconocer una autoridad política no debe llevar a la conclusión que la legitimidad política se deriva sólo de la justificación de tal autoridad. La autoridad de tomar decisiones vinculantes no libera de las exigencias de la argumentación autónoma. Es un instrumento para realizarla, no para reemplazarla ${ }^{11}$.

${ }^{10}$ Que garantiza, a diferencia del particularismo del decreto, la aplicación de las pretensiones normativas aprobadas por la ciudadanía a la totalidad de los individuos involucrados

${ }^{11}$ Sieyes, E. ¿Qué es el tercer estado?: Ensayo sobre los privilegios, Madrid, Alianza, 2003, págs. 112 y 154. 
Así las decisiones de los poderes mayoritariamente elegidos pueden ser consideradas presuntamente legítimas, o legítimas prima facie por razones pragmáticas de organización de la convivencia ${ }^{12}$.

En términos más esquemáticos y considerando la imposibilidad de establecer mecanismos de participación directa que garanticen en plazos razonables la obtención de un consenso ideal, la propia necesidad de resolver el problema de la producción de normas comunes en sociedades complejas nos conduce, racionalmente, a la delegación de la argumentación autonóma y al recurso al voto ${ }^{13}$. Así, los intereses de la población se verían reflejados en principio en el poder legislativo, que por su carácter electivo y colegiado es el más apto para representar al conjunto de la población -o cuanto menos a los intereses predominantes de ésta-. Así el poder legislativo sanciona normas de carácter general bajo el escrutinio electoral de la población, y determina a través de estas también las competencias de los otros poderes.

${ }^{12}$ Esto resulta más claro si lo vemos desde la perspectiva de la argumentación natural propuesta por Toulmin. En la práctica discursiva un hablante no necesita justificar cada afirmación que realiza, sino solo aquellas que se vean cuestionadas por otro participante en la argumentación, del mismo modo, en una democracia operamos según la presunción de que la voluntad de la mayoría representada en el parlamento es un buen comienzo para obtener una decisión que tienda a la imparcialidad, no obstante lo cual contamos con procedimientos para verificar la justificación de cualquier decisión de esta clase y, en su caso, modificarla. Ver Toulmin, S. The uses of Argument, Cambridge, Cambridge University Press, 2003, cap. 2.

${ }^{13}$ Que es una herramienta más económica que la argumentación para determinar las convergencias morales y políticas de la sociedad. No obstante, debe tenerse en cuenta que el voto únicamente permite identificar convergencias, pero nada nos dice respecto de la razonabilidad de sus resultados. La tradición política liberal resolvía este problema a través de la invocación de derechos sustantivos que limitarían el accionar del soberano. Por el contrario, en el marco de la tesis de la argumentación autónoma, es la propia racionalidad de la democracia la que exige la existencia de mecanismos de control que permitan verificar las ponderaciones cedidas al legislador. Ver más adelante las secciones sobre convergencia normativa y sobre derechos fundamentales. 
En tanto resulta irracional pretender que todos y cada uno de los ciudadanos participen de modo directo en la producción del derecho, resulta racional atribuir al Estado democrático el monopolio de la determinación del derecho vinculante; pero solo en la medida en que resulta instrumental a una ponderación imparcial (y por ende aceptable) de los diversos intereses de quienes constituyen la ciudadanía, en equilibrio con la necesidad práctica de contar con un juego de reglas relativamente estable para resolver los conflictos entre individuos. De este modo el derecho vigente (que incluye toda producción normativa proveniente del estado: leyes, decretos y sentencias), puede ser reconstruido como el "destilado" de los consensos morales de una sociedad. Prima facie válido ${ }^{14}$ en tanto haya respetado los mecanismos formales de producción, pero necesariamente recurrible en tanto eleva la pretensión de ser la mejor interpretación del conjunto de razonamientos autónomos de la población.

\section{I.3 Democracia y convergencia}

Una vez definido qué es lo que se entiende por racionalidad democrática se hace preciso indagar con un poco más de profundidad en la cuestión de la convergencia valorativa.

La convergencia valorativa guarda con el procedimiento argumentativo una relación de mutua complementariedad que en mi opinión no se encuentra adecuadamente desarrollada en el trabajo que discutimos. Si bien es cierto que, a través de la argumentación es posible avanzar hacia una cierta convergencia razonable en términos de armonización de los intereses de los participantes, también es cierto que la argumentación racional en el marco de las democracias modernas sólo es posible en la medida en que se presupone una mínima convergencia respecto de (i.) la utilización de la argumentación en lugar de la fuerza como medio de resolución de los conflictos de intereses, (ii.) el diseño de los mecanis-

${ }^{14}$ Este es un punto difícil de determinar con precisión. En principio podríamos afirmar que es oponible automáticamente a la población, no obstante esta situación cambiaría si en el caso concreto se muestra que vulnera excesivamente la autonomía de los ciudadanos. 
mos a través de los cuales el procedimiento argumentativo se ve institucionalizado, y (iii.) la determinación de una constelación de garantías mínimas comunes para el ejercicio del razonamiento autónomo que podríamos denominar derechos fundamentales ${ }^{15}$.

Por otro lado, no debemos olvidar que a la base de todo el sistema tenemos individuos portadores de intereses, ponderando las diversas posibilidades antes de tomar una decisión racional al respecto. La democracia puede ayudar a la convergencia, pero no puede construirla desde cero ${ }^{16}$. Para que la democracia funcione no hace falta que todos tengamos los mismos derechos, hace falta que todos tengamos las mismas necesidades, solo de la comunidad de intereses puede surgir una ley que protegiendo el interés de todos proteja el de cada uno ${ }^{17}$.

\section{I.4 El rol de los derechos fundamentales en los Estados Democráticos}

En la medida en que la argumentación autónoma constituye la base de la legitimidad de los estados democráticos, no es posible eliminar

${ }^{15}$ La presentación es analítica ya que los tres grados se encuentran implicados entre sí. El tercer grado impacta en los otros dos, prefigurando una estándar de autonomía individual que condiciona los consensos obtenidos respecto de éstos, como muestran los trabajos de N. Fraser, I. Young o J. Cohen, entre otros. A su vez, la potencial desnaturalización de la argumentación que pueda producir una institucionalización deficiente o asimétrica de la argumentación en el segundo grado no sólo invalida los resultados obtenidos en el tercero, sino que justifica y hace razonable el rechazo del primer grado por aquellos que se vean sistemáticamente excluidos. Ver, entre otros, Gargarella, R. El derecho a la protesta, Buenos Aires, Ad-Hoc, 2005.

${ }^{16}$ Rousseau llegó a ver este problema con una claridad notable, y de ahí su aparente obsesión con la igualdad material, la religión civil y su rechazo de las facciones, tres ideas mal comprendidas por el liberalismo en términos de un altruismo autoritario. Cada individuo necesita obtener algo a cambio de someterse a la voluntad general y si cada individuo necesita obtener algo distinto, entonces carece de sentido que intenten encontrar una solución común.

${ }^{17}$ Desde esta perspectiva se ve que muchos de los problemas que tradicionalmente se atribuyen a la democracia o a la debilidad de sus instituciones tienen más que ver con las desigualdades económicas y culturales que fracturan a una sociedad que con la democracia en sí misma. 
la primera sin perder la segunda. En este sentido, ante un caso que implique la imposibilidad del ejercicio de la argumentación autónoma, que además se encuentre razonablemente justificada, nos encontramos frente a un límite intrínseco a la actividad del legislador ${ }^{18}$. Tanto la argumentación como la ponderación autónoma no son operaciones matemáticas realizadas por computadoras en abstracto, sino que se trata de evaluaciones, individuales y colectivas, sobre intereses concretos de personas concretas, realizados en un contexto histórico, social, cultural y económico específico. Si un Estado censura los medios de comunicación, impide un ejercicio adecuado del razonamiento autónomo, pues priva a los ciudadanos de información relevante para tomar decisiones; pero del mismo modo, si el estado falla en garantizar condiciones mínimas de existencia para la población ${ }^{19}$ también está impidiendo el adecuado ejercicio del razonamiento autónomo.

De este modo es posible reconstruir el catálogo de derechos liberales como un primer intento por definir las condiciones de ejercicio del razonamiento autónomo: condiciones materiales (propiedad, industria y libre circulación), condiciones sociales (igualdad formal ante la ley), condiciones culturales (libertad de prensa, de enseñanza y de conciencia). Estos eran, como muestra Habermas ${ }^{20}$, los intereses que esa clase, que era la burguesía ilustrada, logró introducir en la naciente esfera pública productora de derecho. La tesis de la argumentación autónoma nos permite evitar una visión sustancialista de este catálogo de omisiones y prestaciones estatales. Lo que hay es una hipótesis respecto de las garantías mínimas que debe brindar el estado para resultar aceptable a la sociedad civil, que al ser contrastada únicamente por otros miembros de la misma categoría, es considerada en la época legítima y adecuada. La gradual apertura del juego de producción del derecho a otros géneros, otras clases, otras etnias, etc., permitió poner

${ }^{18}$ Sieckmann, J. op.cit., 2012, cap. 8.

${ }^{19}$ Sin importar la cantidad de población que se encuentre en esa situación, del mismo modo que la censura de un medio de comunicación es tan criticable como la censura de muchos.

${ }^{20}$ Ver Habermas, G., Historia y Crítica de la Opinión Pública, Barcelona, Gustavo Gili, 2004, pág. 175. 
en cuestión esa hipótesis, y modificar y extender o restringir según el caso aquel juego de garantías originales.

Por ser dependiente de la argumentación, resulta imposible definir de modo sustancial ${ }^{21}$ el contenido de los derechos fundamentales, pero si es posible ver que, estructuralmente, existen una serie de condiciones muy cercanas al núcleo de lo que cada época entiende por autonomía, cuya vulneración por parte del Estado no puede ser tolera$\mathrm{da}^{22}$. Nuevamente, en una sociedad económica, social y culturalmente homogénea este núcleo de condiciones mínimas es muy sencillo de determinar, por el contrario, en sociedades fracturadas, ya sea por la desigualdad económica, la religión o la ideología, es poco probable que todos acuerden en un límite común.

En este sentido la tesis de la argumentación autónoma impone una fuerte carga al Estado en términos de garantía integral de la autonomía de la población, tanto para aquellas de la tradición liberal, social y post social, ya que estas no constituyen un programa político, y por lo tanto al arbitrio de los poderes públicos, sino condiciones de legitimidad de la autoridad de las instituciones políticas, y por ende directamente exigibles.

\section{I.5 El potencial democrático del poder judicial}

En el modelo de la argumentación autónoma el poder judicial puede reclamar, entonces, dos funciones de control. Por un lado se preserva su rol tradicional de verificar que las decisiones de los poderes públicos se adecuen a lo que la sociedad considera "derechos constitucionales". Esto implica por un lado revisar el accionar (omisivo, insuficiente o excesivo) de las otras ramas del gobierno respecto de aquellos casos fáciles ${ }^{23}$ (violencia institucional, censura, tortura, vulneración

${ }^{21}$ Ver Sieckmann, J. "Autonomía Moral y Legitimación Democrática”, n. ${ }^{\circ}$ 51.

${ }^{22}$ Ver el análisis de la prohibición de exigencia de lo insoportable en Clérico, L. El examen de proporcionalidad, Buenos Aires, Eudeba, 2009, cap.3.

${ }^{23} \mathrm{La}$ facilidad o dificultad del caso dependerá en este modelo, del nivel de convergencia existente respecto de una solución razonable. 
de la propiedad, etc.), como así también armonización de ponderaciones diversas cuando se trata de normas sobre las que no existe tanto acuerdo (vivienda, salud, educación, libertad de conciencia, autonomía sobre el propio cuerpo, etc.).

Pero además el poder judicial puede jugar, dadas ciertas condiciones, un rol democrático en términos de rectificación del proceso de deliberación pública. Una vez que hemos removido la legitimidad originaria del Parlamento, para reubicarla en la ciudadanía, reemplazándola con una legitimidad derivada, aunque prima facie vinculante por el lugar específico que juega el poder legislativo en la democracia representativa, la tesis de la representación argumentativa sostenida por Alexy se vuelve mucho más plausible. Como señala Sieckmann, el parlamento presenta, a pesar de sus virtudes, una serie de defectos ${ }^{24}$.

Entre estos se destaca el uso de la votación como criterio para la toma de decisiones. A diferencia de los actos administrativos y de las sentencias judiciales, que tienen una fuerte pretensión de corrección y de hecho resultan impugnables ante la ausencia de justificación razonable, la figura de la exposición de motivos juega un papel mucho más superficial en la sanción de las leyes. Esto resulta entendible pues, en primer lugar se trata del poder público más vulnerable al control popular, y en segundo lugar es el más proclive al establecimiento de compromisos políticos - que de algún modo le generan una mayor tendencia a la imparcialidad que la que posee el poder ejecutivo-. Pero, al mismo tiempo, le da al parlamento un enorme margen de discrecionalidad que colisiona por un lado con el carácter supra legal de los derechos fundamentales, y por el otro convierte a la delegación legislativa en una suerte de cheque en blanco ${ }^{25}$. Otro defecto estructural del Parlamento radica en su carácter mayoritario. En la medida en que lo que motiva a los legisladores es la obtención del mayor número de votos posibles en la contienda electoral, difícilmente van a dedicarse

${ }^{24}$ Ver Sieckmann, J. "Autonomía moral y legitimidad democrática", pág. 32.

${ }^{25}$ Aunque volveremos sobre el punto más adelante, justamente la función de los otros poderes, y en particular del poder judicial a través del control de constitucionalidad, radica en "testear" la imparcialidad de la fundamentación de los actos legislativos. Ver Sieckmann, J. op.cit. pág. 34. 
a discutir problemas e intereses de los sectores minoritarios de la población ${ }^{26}$. Estos dos problemas tornan necesario el establecimiento de un sistema de controles respecto del poder legislativo ejercido a través de la representación ${ }^{27}$.

Es en este contexto que el poder judicial aparece como el espacio idóneo para la representación argumentativa. Como señalamos más arriba, ni el poder legislativo ni el poder ejecutivo admiten en general la participación directa de la población. Es sólo en los tribunales que el ciudadano tiene la posibilidad de esgrimir sus intereses y sus razones al margen de las mayorías electorales y de las presiones políticas y económicas. A esto se refiere R. Alexy con el concepto de "representación argumentativa" 28 . Naturalmente, el recurso a los tribunales sólo resulta razonable en la medida en que nos enfrentamos bien a un parlamento sordo, o bien a grupos minoritarios o subordinados. En otros términos, podemos presumir, usualmente, la legitimidad democrática -entendida como imparcialidad en la argumentación- de las normas sancionadas por el parlamento, pero al mismo tiempo la garantía del principio de autonomía nos obliga a mantener un espacio institucionalizado a través del cual esa argumentación que justifica las leyes vigentes, pueda ser reabierta, con una serie de condiciones.

La tesis de la ponderación autónoma nos brinda una serie de criterios normativos para evaluar tanto la performance democrática pro-

${ }^{26} \mathrm{Y}$ cuando lo hacen es en general porque estos intereses minoritarios han logrado imponerse en la agenda pública de modo tal que han logrado captar la atención de las mayorías, tal como el caso de matrimonio igualitario en la Argentina. Ver en este trabajo 2.2.

${ }^{27}$ Además de estos problemas, propios de cualquier parlamento nacional, en ciertos casos podemos encontrarnos con que los legisladores no representan efectivamente a la población, generando distorsiones respecto de los efectivos intereses de esta. Esto puede deberse a diversos motivos, desde el ejercicio del lobby por parte de grupos de presión al predominio de las élites sociales en el parlamento, por mencionar sólo algunos. De todos modos estas distorsiones, a diferencia de las mencionadas en el párrafo anterior, deben ser argumentadas en cada caso.

${ }^{28}$ Ver Alexy, R. "Balancing, Constitutional Review and Representation", I-CON, vol.3, n. ${ }^{\circ} 4,2005$, págs. 572-581. 
piamente dicha de las instituciones, como la performance argumentativa que se vinculan a las posibilidades efectivas de presentación de argumentos por parte de los individuos autónomos, la igualdad ${ }^{29}$ en la consideración de sus pretensiones normativas, la corrección de las premisas empíricas, etc ${ }^{30}$.

\section{Autonomía y Democracia: la performance argumentativa como criterio normativo}

En lo que sigue voy a analizar algunos ejemplos concretos y contrapuestos -bastante trabajados por la dogmática constitucional-que permiten demostrar el potencial de la tesis de la argumentación autónoma.

\section{II.1 El ejercicio contra mayoritario de la función jurisdiccional}

En su análisis sobre el carácter contra mayoritario del proceso constitucional norteamericano, Gargarella ${ }^{31}$ describe el contexto en el que surge la polémica entre federalistas y anti federalistas en torno de la estructura política y jurídica que debe adoptar la nueva nación. Luego de declarada la independencia, los comerciantes ingleses exigirán a sus pares americanos el pago de sus deudas en "moneda dura", amenazando con ahogar el intercambio comercial entre Europa y las colonias. Frente a esta situación, los comerciantes norteamericanos trasladan el peso de la deuda a los pequeños propietarios y granjeros, de los cuales eran a su vez acreedores, amenazándolos con la pérdida de sus tierras y la prisión ${ }^{32}$. Todavía inmersos en el clima participativo gestado durante la guerra de independencia, la respuesta de los pequeños propietarios va a tomar dos

${ }^{29}$ Lo que excede la mera igualdad formal y nos conduce al problema de las fórmulas de igualdad. Ver Clérico, L. y Aldao, M. "La igualdad como redistribución y como reconocimiento: derechos de los pueblos indígenas y la Corte Interamericana de Derechos Humanos", Estudios Constitucionales, vol.9, . $^{\circ} 1,2011$.

${ }^{30}$ Ver Sieckmann, J. "Autonomía moral y Legitimidad Democrática”, pág. 23.

${ }^{31}$ Gargarella, R. Nos los representantes, Buenos Aires, Miño y Dávila, 1995.

${ }^{32}$ Gargarella op.cit., págs. 45-49. 
vías. Por un lado una serie de revueltas populares con el objeto de frenar los procesos judiciales por deudas (que en el período aumentan en más del doscientos cincuenta por ciento) ${ }^{33}$. Por el otro, y frente a la docilidad de las cortes frente a los intereses de los comerciantes ${ }^{34}$, algunas legislaturas locales van a proteger los intereses de los deudores a través de la emisión e imposición de papel moneda ${ }^{35}$. Tanto Madison como Hamilton van a criticar duramente estas experiencias, calificándolas el primero de "traicionera usurpación" de las legislaturas ${ }^{36}$ y el segundo de leyes que violan los contratos privados, infracciones que deben ser sancionadas por las armas ${ }^{37}$. En el mismo sentido, en el número X de $E l$ Federalista se afirma que el principal objetivo de la constitución consiste en dominar el espíritu de partido, explicitando un poco más adelante que por partido se entiende a la mayoría conformada por los deudores, cuyos intereses predominaban en las asambleas locales ${ }^{38}$. Esta lectura se ve confirmada con la interpretación de J. Nedelsky ${ }^{39}$. Como muestra el detallado análisis de esta autora, la constitución norteamericana fue diseñada con el objeto de garantizar la seguridad de una esfera privada mercantilmente entendida frente a la "tiranía" de una mayoría que, ante el cambio imprevisto de las condiciones del mercado, trata desesperadamente de mantener sus medios de vida ${ }^{40}$.

${ }^{33}$ La más notable de éstas fue la organizada por Shays en Massachusetts, que servirá de argumento para el establecimiento de la Unión en el número IV de Hamilton, M.; Madison, J. y Jay, J., El Federalista, México, FCE, 1957.

${ }^{34}$ Gargarella, op.cit. pág. 50.

${ }^{35}$ El caso más notable fue el del legislador Hazard, de Rhode Island, que también sirve a los autores del Federalista como ejemplo de aquello que la constitución debe evitar.

${ }^{36}$ En la Segunda Carta desde Phocion, de 1784.

${ }^{37}$ Hamilton, M.; Madison, J. y Jay, J., op.cit., cap. VII.

38 Ibid., pág. 36.

${ }^{39}$ Nedelsky, J. Private property and the limits of American Constitutionalism: The Madisonian framework and its legacy, Chicago, University of Chicago Press, 1990.

${ }^{40}$ Nedelsky, J. op.cit., pág. 2. Por otro lado resulta notable que la legitimidad que le proviene al gobierno del respeto a ciertos derechos individuales, que en la Declaration of Independence eran la vida, la libertad y la búsqueda de la 
A pesar del lenguaje, es importante comprender que no se trata, al menos no abiertamente, de la intención de imponer los intereses de una clase sobre otra. Las múltiples referencias a la íntima conexión entre comercio y prosperidad de la nación dejan ver la presencia de la "pretensión de corrección" que Alexy atribuye a los Estados constitucionales ${ }^{41}$. Allí donde el comercio y la industria prosperen todos se verán beneficiados, y la desigual distribución de la propiedad no es el objetivo, sino la condición de posibilidad de este proyecto jurídico, político y económico ${ }^{42}$.

Así, las clases más altas argumentan y justifican las medidas que pretenden imponer en términos del beneficio de todos los habitantes. No obstante, también son conscientes de que, dada la disparidad de condiciones entre ellos y la mayoría del pueblo, difícilmente logren alcanzar lo que Sieckmann denomina una "convergencia razonable".

En la medida en que la democracia directa, descrita como irracional y apasionada en numerosos pasajes de El Federalista, puede poner en evidencia la falta de consideración de los intereses de los granjeros, los federalistas necesitan sustraer la cuestión de la propiedad de la esfera de lo públicamente discutible (asimilándola a los derechos fun-

felicidad, es aprovechada por Madison en la redacción de la Constitución de Virgina, pero con la introducción de la propiedad entre aquellos derechos que es propósito del gobierno garantizar. Ver Nedelsky, J. op.cit., pág. 151. Más adelante, en el número X de El Federalista se afirma: El primer objeto del gobierno es la protección de esas facultades. La protección de las facultades diferentes y desiguales para adquirir propiedad. Los federalistas, además, delinean una esfera privada propietaria de modo indirecto, a través de la restricción de la soberanía popular, de las competencias de las legislaturas locales dóciles a ésta, y la prohibición explícita de emitir papel moneda y devaluar a los Estados. En este sentido en el mismo número se califica de medidas disparatadas y perniciosas el entusiasmo por el papel moneda, por la abolición de las deudas y por el reparto de la propiedad. Para un análisis detallado de los fallos de la Corte Suprema de ese país que van a reforzar la sustracción de la cuestión de la propiedad del ámbito de lo públicamente discutible cf. Nedelski, J. op.cit. pág. 188 y ss.

${ }^{41}$ Alexy, R. "Los principales elementos de mi teoría del derecho", Doxa, 32, 2009.

${ }^{42}$ Ver Nedelsky, J. op.cit., pág. 167. 
damentales de la Unión) y por otro lado, y esto es más relevante aún, tienen que restringir los canales de acceso a los ámbitos de creación, aplicación e interpretación de las normas.

Para alcanzar este objetivo se toman tres caminos simultáneos. En primer lugar se trata de aislar al poder judicial de las influencias populares. En este sentido se ubican las cortes federales por encima de las locales, se reserva al senado la selección de los magistrados y se rechaza el juicio por jurados para las causas civiles. En segundo lugar se trata de escindir la esfera pública del ámbito de participación popular. En este sentido se prefieren grandes distritos electorales, la elección indirecta de los funcionarios públicos, $\mathrm{y}$, fundamentalmente, aún cuando se reservan ciertas autonomías a las instituciones locales (que irán desapareciendo gradualmente, sobre todo después de la guerra de sección), se les imponen una serie de límites, entre ellos la definición de la propiedad privada, que podrán ser reforzados con las armas por el gobierno federal. En tercer lugar los federalistas toman una serie de medidas institucionales que, además de su carácter contra mayoritario, producen el efecto de escindir aún más los ámbitos de producción del derecho de los ámbitos en los que los ciudadanos pueden hacerse oir. A saber, elecciones indirectas, mandatos extensos, ejecutivo unipersonal con la facultad de nombrar funcionarios públicos, veto presidencial, prioridad del senado respecto de la cámara baja, calificación propietaria para integrar el senado, etc. ${ }^{43}$.

Lo que resulta relevante en este caso es que, en esta coyuntura específica, las instancias legislativas resultan mucho más representativas de los intereses de la población, y parece razonable concluir que de haberse dado una verdadera ponderación de los intereses en juego, la historia hubiese sido diferente. De hecho es posible reconstruir todo el proceso como la sucesiva alienación de la población respecto de la producción y justificación del derecho, con el fin de garantizar la preservación de intereses que no resistían la menor deliberación pública. La judicialización en este caso es un problema, pero solo en tanto es instrumental a la 
restricción de la deliberación. Como veremos en el caso que sigue, este carácter restrictivo no es intrínseco a la función jurisdiccional.

\section{II.2 La democracia en los tribunales}

En el extremo opuesto nos encontramos con el proceso que condujo a la sanción de la ley n. ${ }^{\circ} 26618$ (de Matrimonio Igualitario) en julio del año 2010 en la Argentina. El art. 14 de la Constitución Nacional impone al Estado, entre otras obligaciones, la protección integral de la familia; mandato constitucional que se entendía satisfecho a través de la regulación legislativa de esta institución social. Hasta esa fecha los artículos correspondientes del Código Civil requerían consentimiento expreso, ante autoridad competente, de hombre y de mujer para reconocer la existencia de un matrimonio, que es la figura jurídica a través de la cual las familias ven reconocidos sus derechos. A la vez, en una interpretación literal de la norma, los oficiales de los Registros Civiles se negaban a dar turnos para contraer matrimonio a parejas conformadas por personas del mismo sexo.

Ahora bien, según un informe del INDEC del año 2010, un 0,33 \% de las parejas convivientes en el país están conformadas por personas del mismo sexo ${ }^{44}$.

Desde una comprensión mayoritaria de la democracia parece evidente que la ampliación de la figura del matrimonio no es una cuestión relevante, y así parece haberlo entendido el poder legislativo. En la década del 90 la Asociación Gays por los Derechos civiles había intentado impulsar, sin resultado, una ley de matrimonio civil. En diciembre de 1998 la Sociedad de Integración Gay Lésbica Argentina (SIGLA) logró presentar un proyecto de ley de Unión Civil para parejas del mismo sexo ${ }^{45}$ que logró tomar estado parlamentario, estado que perdió y fue vuelta a presentar, sin éxito, en los años 2000, 2002

${ }^{44}$ INDEC, "Análisis de datos: parejas convivientes del mismo sexo", Censo Nacional de Población, Hogares y Viviendas 2010.

${ }^{45}$ Expediente número D-7816-98 (estado parlamentario en la Cámara de Diputados de la Nación). 
y $2004^{46}$. En el año 2005 la Comunidad Homosexual Argentina presenta un proyecto de Unión Civil Nacional que perdería estado parlamentario en 2006. En el año 2007 se presentarían dos proyectos similares que correrían la misma suerte. Es importante señalar que todos estos reclamos fueron rechazados sin justificación alguna.

De hecho no es hasta el año 2009, con la resolución del caso Freyre por el fuero Contencioso Administrativo y Tributario de la Ciudad Autónoma de Buenos Aires que los intereses y argumentos del colectivo GLBT comienzan a ser considerados seriamente por las instancias de gobierno. Trasladado el problema a los tribunales, es posible plantear la cuestión no en términos de número de afectados, sino de respecto de la dignidad y autonomía de una parte de la ciudadanía. El punto ya no es la cantidad de votos implicados, sino la consistencia de los argumentos que fundamentan la interpretación restrictiva de la manda constitucional de protección integral de la familia.

Intentemos entonces, reconstruir la ponderación que condujo al legislador a restringir el matrimonio a parejas del mismo sexo. Retomando el trabajo de Clérico, podemos identificar los siguientes argumentos que justificaban la interpretación restrictiva: $a$. la voluntad del legislador histórico, $b$. la interpretación literal del género en el texto, $c$. el argumento de la procreación y $d$. la necesidad de proteger a los menores de ser adoptados por parejas del mismo sexo ${ }^{47}$. Aceptar el primero, implicaría que el derecho al voto puede ser ejercido sólo por los hombres, ya que esa era la voluntad del constituyente originario, afirmar la segunda nos obliga a realizar una enmienda constitucional para permitir el acceso de las mujeres a los cargos políticos enumerados en la Constitución, el argumento de la procreación nos llevaría a excluir del matrimonio a las parejas incapaces de concebir (de cualquier orientación sexual) y el cuarto había sido refutado por numerosos trabajos empíricos. Así estamos frente a un caso de argumentación deficiente por parte del le-

${ }^{46}$ Expediente número D- 1158-00 (estado parlamentario en la Cámara de Diputados de la Nación).

${ }^{47}$ Clérico L. "El matrimonio igualitario y los principios estructurantes de igualdad y/o autonomía", en Clérico/Aldao (eds.), Matrimonio Igualitario, Buenos Aires, Eudeba, 2010. 
gislativo, en tanto no se cumplen ni los requisitos de consistencia de la fundamentación ni corrección de las premisas empíricas, cuya revisión requirió la intervención del poder judicial.

Lo que impedía la discusión legislativa no era la parcialidad de la demanda, los trabajos de Clérico y Gargarella ${ }^{48}$ sobre la discusión constitucional en torno al Matrimonio Igualitario muestran con claridad que se trataba de un caso evidente de discriminación injustificada en términos argumentativos. Que el colectivo LGBT tenga la opción de contraer matrimonio es una inferencia del principio de igualdad. Quien acepta el juego de la democracia, acepta sujetar sus intereses y pretensiones a la argumentación. No obstante, la estructura misma del poder legislativo impedía que los intereses y argumentos del colectivo GLBT fueran tomados en serio por los legisladores. Si esencializamos el concepto de democracia, y lo confundimos con el de representación, no nos queda otra que calificar este proceso de "contra mayoritario", no obstante, y esto es probablemente lo más interesante, una vez que el debate tomó estado público, el parlamento reprodujo el debate, ponderó los argumentos relevantes de ambas posiciones y terminó por confirmar la solución a la que habían llegado los jueces del fuero Contencioso Administrativo de la Ciudad Autónoma de Buenos Aires. Más aún, la población parece haber aceptado sin problemas el cambio legislativo ya que no se registraron revueltas ni grandes movilizaciones en contra de la decisión, con lo que ni siquiera podemos afirmar que la posición anterior, restrictiva respecto del matrimonio, calificaba siquiera como "consenso mayoritario" 49.

${ }^{48}$ Gargarella, R. "Matrimonio y Diversidad Sexual: el peso del argumento igualitario", en Clérico y Aldao, op.cit. págs. 132-144.

${ }^{49}$ Aunque es imposible abordarlo en este trabajo, otro buen ejemplo del rol democrático que pueden jugar los tribunales en términos de reproducción imparcial de la discusión pública frente a la evidente parcialidad de los poderes con presunta legitimación democrática lo constituye el caso de la Asamblea de Esquel y la resolución a la que llegó finalmente la Corte Suprema de Justicia. Al igual que en el caso anterior, nos encontramos frente a poderes públicos que explícitamente desoyen los argumentos e intereses de la población,puesto que en este caso se contaba con un referendo popular que dejaba ver con claridad los resultados de la "argumentación 


\section{Bibliografía}

Aldao, M. "Teoría de la argumentación y democracia", Revista Gioja, $1,2007$.

Aldao, M. "Racionalidad, derecho y democracia", en Clérico, L. y Sieckmann, J. (eds.) La teoría del Derecho de Hans Kelsen, Bogotá, Externado, 2011.

Alexy, R. "Los principales elementos de mi teoría del derecho", Doxa, 32, 2009.

Alexy, R. "Balancing, Constitutional Review and Representation", I-CON, vol. 3, 4, 2005, págs. 572-581.

Clérico, L. "El matrimonio igualitario y los principios estructurantes de igualdad y/o autonomia", en Clérico, L. y Aldao, M. (eds.), Matrimonio Igualitario, Buenos Aires, Eudeba, 2010.

Clérico, L. El examen de proporcionalidad, Buenos Aires, Eudeba, 2009, cap. 3.

Clérico, L. y Aldao, M. "La igualdad como redistribución y como reconocimiento: derechos de los pueblos indígenas y la Corte Interamericana de Derechos Humanos", Estudios Constitucionales, vol.9, n. ${ }^{\circ} 1,2011$.

Gargarella, R. "Matrimonio y Diversidad Sexual: el peso del argumento igualitario", en Clérico, L. y Aldao, M. (eds.), Matrimonio Igualitario, Buenos Aires, Eudeba, 2010, págs. 132-144.

Gargarella, R. El derecho a la protesta, Buenos Aires, Ad-Hoc, 2005.

Gargarella, R. Nos los representantes, Buenos Aires, Miño y Dávila, 1995.

Habermas, J. "Ética del Discurso: notas sobre un programa de fundamentación", en Conciencia moral y acción comunicativa, Madrid: Trotta, 2008.

Habermas, J. Facticidad y Validez, Madrid, Trotta, 2005, pág. 373.

Habermas, J. Historia y Crítica de la Opinión Pública, Barcelona, Gustavo Gili, 2004, pág. 175. el los valores del progreso productivo y el medio ambiente sano. 
Hamilton, M.; Madison, J. y Jay, J., El Federalista, México, FCE, 1957. INDEC, "Análisis de datos: parejas convivientes del mismo sexo", Censo Nacional de Población, Hogares y Viviendas 2010.

Nedelsky, J. Private property and the limits of American Constitutionalism: The Madisonian framework and its legacy, Chicago, University of Chicago Press, 1990.

Oquendo, A. "El dilema entre la autonomía pública y la privada: reflexiones y contra-reflexiones", Revista Jurídica de la Universidad de Palermo, 4, 1999.

Sieckmann, J. The logic of autonomy, Oxford, Hart Pub., 2012.

Sieckmann, J. "El concepto de autonomía", Doxa, 31, 2008.

Sieckmann, J. "Basic Rights in the Model of Principles", en IVR, ARSP, 67, 1997.

Sieckmann, J. "Autonomía moral y legitimidad democrática" en este número.

Sieyes, E. ¿Qué es el tercer estado?: Ensayo sobre los privilegios, Madrid,Alianza, 2003, págs. 112 y 154.

Toulmin, S. The uses of Argument, Cambridge, Cambridge University Press, 2003, cap. 2. 